\title{
PENGARUH FAKTOR-FAKTOR INTERNAL DAN EKSTERNAL TERHADAP PENGEMBANGAN INDUSTRI KELAPA DI KABUPATEN INDRAGIRI HILIR
}

\section{Influence of Internal and External Factors Towards to Development of Coconut Industry in Indragiri Hilir District}

\author{
Nusyirwan.Ry ${ }^{1}$, Djaimi Bakce ${ }^{2}$ dan Jumatri Yusri ${ }^{2}$ \\ ${ }^{1}$ Mahasiswa Pasca Sarjana Fakultas Pertanian Universitas Riau \\ ${ }^{2}$ Dosen Jurusan Agribisnis Fakultas Pertanian Universitas Riau \\ [Diterima: Juli 2017; Disetujui: Agustus 2017]
}

\begin{abstract}
Indragiri Hilir District has 515,200 hectares of local coconut land with production of 418,200 tons (Statistic Board, 2015), but the area of land and its production is always decreasing. The decline of the area is caused by land damage, land conversion, the number of coconut plants that are old and dead and so affect to the need of raw materials for the development of the coconut industry in generating the number and type of product diversification. This research is conducted to analyze the internal and external factors that were influences to the development of local coconut industry which aims to know the internal and external factors in the development of coconut industry in Indragiri Hilir district. The result of the analysis showed that the internal factors that become the strength and impact on the development of the coconut industry are the large area of coconut plant that is large enough, the availability of a large workforce and already has a large scale coconut processing industry; while the weakness factor is the age of coconut plants is quite old, coconut farmers generally use local seeds, decreased coconut productivity and the limited number and type of diversification of coconut derived products. External factors that become opportunities for the development of the coconut industry is the high demand for coconut products and derivatives in the export market, coconut derivative products can still be developed and supported by local government and related agencies while external factors are a threat to the coconut industry development of coconut plantation damage due to sea water intrusion and high investment concerns in competing countries against the coconut industry.
\end{abstract}

Keywords: Rice, Price Fluctuation, Price Variation, Variation coefficient

\begin{abstract}
ABSTRAK
Kabupaten Indragiri Hilir memiliki 515.200 ha lahan kelapa lokal dengan produksi 418.200 ton (BPS, 2015), namun luas lahan dan produksinya selalu menurun. Penurunan luas disebabkan oleh kerusakan lahan, konversi lahan, jumlah tanaman kelapa yang sudah tua dan mati sehingga mempengaruhi kebutuhan bahan baku untuk pengembangan industri kelapa dalam untuk menghasilkan jumlah dan jenis diversifikasi produk. Penelitian ini dilakukan untuk menganalisis faktor-faktor internal dan eksternal yang mempengaruhi pengembangan industri kelapa lokal yang bertujuan untuk mengetahui faktor internal dan eksternal yang mempengaruhi pengembangan industri kelapa di Kabupaten Indragiri Hilir. Hasil analisis menunjukkan bahwa faktor internal yang menjadi kekuatan dan berdampak terhadap pengembangan industri kelapa adalah luas areal tanaman kelapa yang cukup besar, ketersediaan tenaga kerja yang besar dan sudah memiliki industri pengolahan kelapa skala besar. Sedangkan faktor kelemahannya adalah umur tanaman kelapa sudah cukup tua, petani kelapa umumnya menggunakan benih lokal, menurunkan produktivitas kelapa dan terbatasnya jumlah dan jenis diversifikasi produk turunan kelapa. Faktor external yang menjadi peluang terhadap pengembangan industri kelapa adalah tingginya permintaan produk kelapa dan turunannya di pasar ekspor, produk turunan kelapa masih dapat dikembangkan dan didukung oleh pemerintah daerah dan instansi terkait sedangkan faktor eksternal merupakan ancaman bagi pengembangan industri kelapa adalah kerusakan perkebunan kelapa karena intrusi air laut dan tingginya perhatian investasi di negara-negara pesaing terhadap industri kelapa.
\end{abstract}


Kata Kunci: Fluktuasi Harga, Variasi Harga, Koefisien Harga

\section{PENDAHULUAN}

Kabupaten Indragiri Hilir memiliki 515.200 hektar areal tanaman kelapa dengan 418.200 ton produksi (Badan Pusat Statistik, 2015) yang merupakan wilayah terluas di Provinsi Riau, Asia dan di dunia. Produk industri kelapa telah memberikan porsi $60,59 \%$ terhadap PDRB nilai dan volume ekspor Indragiri Hilir (Dinas Perindustrian dan Perdagangan Kabupaten Indragiri Hilir, 2012).

Perkembangan luas areal dan produksi tanaman kelapa dari tahun ketahun selalu mengalami penurunan. Penurunan luas areal dan produksi tanaman kelapa tersebut disebabkan oleh berbagai faktor antara lain: penurunan luas areal perkebunan kelapa akibat kerusakan lahan akibat intrusi air laut, umur tanaman kelapa sudah tua, petani masih menggunakan bibit lokal. Hal lain yang berkaitan dengan penurunan jumlah luas areal dan produksi kelapa adalah banyaknya petani kelapa yang mengalihkan fungsi lahan ke komoditas lain seperti kelapa sawit karena harga jual kelapa cukup rendah sementara biaya untuk perawatan kebun cukup tinggi serta struktur pasar masih bersifat monopsomi (Bakce, 2015).

Berkaitan dengan permasalahan tersebut di atas, penelitian dilakukan di Kabupaten Indragiri Hilir dengan memilih lokasi penelitian di wilayah Kecamatan Tempuling, Kecamatan Keritang dan Kecamatan Kateman karena wilayah tersebut merupakan wilayah penghasil tanaman kelapa lokal dan berdekatan dengan industri besar pengolahan kelapa lokal yang ada di Kabupaten Indragiri Hilir.

$$
\text { Penelitian dilakukan menggunakan }
$$

Methode SWOT dengan cara melakukan analisa faktor-faktor internal dan external yang berpengaruh terhadap pengembangan industri kelapa di Kabupaten Indragiri Hilir dengan menggunakan matrix IFAS dan EFAS serta matrik IE.

Tujuan dari penelitian ini adalah untuk mengetahui faktor-faktor internal dan external yang berpengaruh terhadap pengembangan industri kelapa lokal di Kabupaten Indragiri Hilir sehingga pengaruh tersebut dapat diatasi oleh pihak-pihak pemangku kepentingan yang terkait dengan cara mencari strategi yang tepat dan akurat untuk pengembangan industri kelapa di Kabupaten Indragiri Hilir sehingga industri kelapa dan turunannya dapat tumbuh dan berkembang di Kabupaten Indragiri Hilir.

\section{METODE PENELITIAN}

Metode penelitian dilakukan pengumpulan data primer dengan cara melakukan review terhadap penelitianpenelitian yang telah dilakukan oleh penelitipeneliti terdahulu yang berkaitan dengan kelapa lokal, baik penelitian yang bersifat regional maupun nasional. Data primer juga didapat dengan melakukan wawancara dengan petani/pedagang pengumpul, tenaga ahli, pihak industri dan pihak pemangku kepentingan. Data sekunder digunakan untuk mendukung data primer yang di dapat dari hasil teview penelitian.

Hasil review terhadap data primer tersebut dilakukan pendalaman ke lapanganan menggunakan metode wawancara dengan menggunakan kuesioner terhadap petani kelapa /pedagang pengumpul, pihak pemangku kepentingan yang terkait dengan pengembangan industri kelapa baik yang ada di provinsi maupun kabupaten antara lain pihak BAPPEDA Kabupaten Indragiri Hilir, Dinas Perindustrian dan Perdagangan Kabupaten Indragiri Hilir, Dinas Perkebunan Kabupaten Indragiri Hilir , Dinas Pertanian Provinsi Riau, Dinas Perindustrian dan Perdagangan Provinsi Riau serta tenaga ahli/akademisi yang memahami tentang perkelapaan lokal di Provinsi Riau.

Analisis data hasil penelitian dilakukan pengolahan secara 2 (dua) tahap yaitu: 1 . Tahap identifikasi faktor internal dan ekxternal dengan menggunakan analisis matrix SWOT (Strength, Weakness, Opportunities and Treaths) yang menjadi kekuatan, kelemahan, peluang dan ancaman terhadap pengembangan industri kelapa di Kabupaten Indragiri Hilir. 2. Tahap evaluasi dilakukan dengan cara menggunakan Internal Factor Evaluation (IFE) dan External Factor Evaluation (EFE) serta matrix Internal dan External.

\section{Matrix Evaluasi Internal Faktor (IFE)}

Analisa terhadap hasil identifikasi faktorfaktor internal (kekuatan dan kelemahan) dilakukan analisa dengan menggunakan matriks 
IFE. Tahapan untuk melakukan analisa terhadap faktor-faktor internal dilakukan dengan cara penentuan bobot nilai mulai dari nilai mulai dari nilai 1 sampai dengan nilai 4 terhadap variabelvariabel yang terdapat pada masing-masing faktor internal menurut tingkat kepentingan dari masing masing variabel, sedangkan penentuan nilai bobot dilakukan dengan metode Kinnear dan Taylor (1991) dengan cara menggunakan bobot yang diberikan kepada setiap variabel dibagi terhadap jumlah nilai bobot keseluruhan variabel dengan menggunakan rumus sebagai berikut:

\section{$\bar{\Sigma}$}

dimana:

$$
\begin{array}{ll}
\alpha \mathrm{i} & =\text { bobot variabel ke- } \mathrm{i} \\
\mathrm{Xi} & =\text { nilai variable ke-i } \\
\mathrm{i} & =1,2,3 \ldots . ., \mathrm{n} \\
\mathrm{n} & =\text { jumlah variable }
\end{array}
$$

Jumlah seluruh nilai bobot harus sama dengan 1,0 .

a. Memberikan nilai peringkat 1 sampai 4 untuk masing-masing faktor yang merupakan kelemahan utama (peringkat $=$ 1), kelemahan kecil (peringkat $=2$ ), kekuatan kecil (peringkat = 3), atau kekuatan utama (peringkat $=4$ );

a. Mengalikan masing-masing nilai bobot dari masing-masing faktor dengan nilai rating/peringkat untuk mendapatkan nilai skor pada faktor internal.

b. Menjumlahkan nilai skor dari keseluruhan variabel untuk mendapatkan nilai total skor. Jika nilai total skor rata-rata di bawah 2,5 menggambarkan bahwa pengembangan industri kelapa berada pada posisi yang lemah secara internal.

\section{Matrix Evaluasi External Faktor (EFE)}

Analisa hasil identifikasi faktor-faktor external (peluang dan ancaman) dilakukan menggunakan matriks EFE. Tahapan analisa dilakukan sebagai berikut:

a. Menentukan bobot setiap variabel faktorfaktor external yang dapat menjadi peluang dan ancaman dengan menggunakan skala $1,2,3$ dan 4 .

b. Skala yang digunakan untuk pengisian kolom dengan memberikan nilai $1=$ jika indikator kurang penting daripada indikator vertikal, nilai $2=$ jika indikator horisontal sama penting dengan indikator vertikal, $3=$ jika indikator horizontal lebih penting daripada indikator vertikal dan $4=$ jika indikator horizontal sangat penting daripada indikator vertikal.

c. Bobot yang diberikan kepada masingmasing variabel mengindikasikan tingkat penting relatif dari faktor terhadap pengembangan industri kelapa dalam di Kabupaten Indragiri Hilir. Jumlah seluruh nilai bobot harus sama dengan 1,0 dengan tahapan memberikan peringkat 1 sampai 4 untuk masing-masing faktor external sebagai berikut:, dimana nilai $4=$ sangat baik, $3=$ respon baik dan rata-rata, $2=$ respon buruk; 1 = respon sangat buruk.

d. Penentuan nilai skor dilakukan dengan cara mengalikan masing-masing nilai bobot faktor dengan peringkatnya dan menjumlahkan nilai skor untuk mendapatkan total nilai skor. Jika total nilai skor dibawah 2,5 menggambarkan masyarakat petani dan industri pengolahan kelapa lokal tidak dapat memanfaatkan peluang atau menghindari ancaman dan tergolong rendah.

e. Penentuan nilai bobot setiap variabel terhadap jumlah nilai bobot keseluruhan variabel dilakukan dengan menggunakan rumus Kinnear dan Taylor (1991) sebagai berikut:

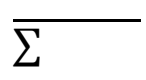

dimana:

$$
\begin{array}{ll}
\alpha \mathrm{i} & =\text { Bobot variabel ke- } \mathrm{i} \\
\mathrm{Xi} & =\text { Nilai variabel ke-i } \\
\mathrm{i} & =1,2,3, \ldots ., \mathrm{n} \\
\mathrm{n} & =\text { Jumlah variabel }
\end{array}
$$

\section{Matrix Internal External (IE)}

Matriks Internal External (IE) digunakan untuk menentukan posisi industri, dimana matrik ini berasal dari berasal dari total nilai bobot IFE dan EFE. Sumbu horizontal merupakan total skor nilai bobot IFE dan sumbu vertikal merupakan total skor nilai bobot EFE. Titik perpotongan antara kedua sumbu tersebut menunjukkan posisi keberadaan industri yang akan dikembangkan serta strategi yang dianggap tepat untuk diterapkan oleh pelaku usaha dan pemangku kepentingan terhadap pengembangan industri kelapa lokal yang ada. 
Nilai total skor IFE ditunjukkan oleh sumbu $\mathrm{X}$ sebesar 1,0 hingga 1,99 merupakan posisi internal lemah, skor 2,0 hingga 2,99 posisi pertimbangan rata-rata, dan skor 3,0 hingga 4,0 adalah posisi yang kuat. Begitu pun dengan nilai total skor EFE yang ditunjukkan oleh sumbu y, dari 1,0 hingga 1,99 adalah posisi rendah, skor 2,0 hingga 2,99 adalah posisi sedang, dan skor 3,0 hingga 4,0 adalah posisi yang tinggi.

Matriks IE dibagi menjadi tiga daerah utama yang memiliki implikasi strategi berbeda satu sama lain yaitu:

a. Rekomendasi yang diberikan untuk divisi yang termasuk ke dalam sel I, II, atau IV adalah sebagai sel yang tumbuh dan pengembangan,

b. Rekomendasi yang diberikan untuk divisi yang termasuk ke dalam sel III, V, VII yaitu dapat dikelola dengan menggunakan strategi menjaga dan mempertahankan penetrasi pasar dan pengembangan produk.

c. Rekomendasi yang diberikan untuk divisi yang termasuk ke dalam sel VI, VIII, IX adalah dilakukan dengan cara tunai dan divestasi.

\section{HASIL DAN PEMBAHASAN}

\section{Internal Factor Analysis (IFAS)}

Hasil dari Internal Faktor Analysis (IFAS) memberikan nilai total skor pembobotan sebesar 2,04 dan berada dibawah 2,5 berarti pengembangan industri kelapa berada pada posisi yang lemah secara internal. Untuk mengetahui lebih detail hasil analisa internal faktor dapat dilihat pada Tabel 1.

Dari Tabel 1, diatas terlihat bahwa faktor kekuatan luas areal tanaman kelapa dalam cukup besar namun masih memiliki berbagai kelemahan seperti umur tanaman kelapa dalam sudah banyak yang tua, petani kelapa dalam pada umumnya menggunakan bibit lokal dan produktivitas tanaman kelapa dalam menurun.

Faktor kelemahan ini dapat diantisipasi dengan cara melaksanakan strategi peremajaan tanaman kelapa dalam yang ada dengan menggunakan bibit unggul lokal sehingga produk dan produktivitas tanaman kelapa yang dihasilkan dapat ditingkatkan. Faktor kekuatan lainnya adalah tersedianya jumlah angkatan kerja yang cukup besar dan telah memiliki industri besar pengolahan kelapa lokal. Hal ini merupakan faktor kekuatan yang sangat kuat untuk pengembangan industri kelapa di Kabupaten Indragiri Hilir, namun demikian sampai saat ini masih memiliki kelemahan yaitu terbatasnya jumlah dan diversifikasi produk turunan kelapa yang dihasilkan.

Hal ini disebabkan oleh rendahnya produktivitas tanaman kelapa yang dihasilkan sehingga kebutuhan bahan baku untuk memproduksi jumlah dan jenis diversifikasi produk turunan kelapa terbatas. Kelemahan lainnya adalah belum adanya program pemberdayaan petani kelapa, masyarakat industri kecil pengolahan kelapa dengan pengusaha industri besar pengolahan kelapa dengan melaksanakan pola kemitraan antara ke tiga pelaku tersebut sehingga potensi kekuatan jumlah angkatan kerja yang cukup besar tersebut belum diberdayakan secara optimal untuk menghasilkan jumlah dan jenis diversifikasi produk turunan kelapa.

Strategi yang dapat dilakukan untuk meningkatkan jumlah dan jenisdiversifikasi produk turunan kelapa adalah dengan cara melaksanakan pembentukan pola kemitraan antara petani kelapa, pengusaha industri kecil dan menengah pengolahan kelapa lokal dan pengusaha industri besar pengolahan kelapa sehingga jumlah dan jenis diversifikasi produk yang dihasilkan dapat ditingkatkan.dan juga dapat dilakukan dengan melaksanakan strategi membuat pmbuatan kebijakan program investasi diversifikasi ptoduk kelapa dalam secara terpadu di Kabupaten Indragiri Hilir.

\section{External Factor Analysis (EFAS)}

Hasil dari External Factor Analysis (EFAS) memberikan nilai total skor pembobotan sebesar 2,24 dan berada dibawah 2,5 berarti masyarakat petani dan industri pengolahan kelapa dalam tidak dapat memanfaatkan peluang atau menghindari ancaman tergolong rendah.

Untuk mengetahui hasil perhitungan nilai total skor pembobotan yang menjadi peluang dan ancaman pada pengembangan industri kelapa dalam lebih detail dapat dilihat pada Tabel 2.

Dari Tabel 2 diatas bahwa faktor external yang menjadi peluang dalam pengembangan industri kelapa di Kabupaten Indragiri Hilir adalah:tingginya permintaaan produk kelapa dan turunannya di pasaran ekspor dan produk turunan kelapa masih bisa dikembangkan serta 
Tabel 1. Total Score Internal Factor Analysis (IFAS)

\begin{tabular}{|c|c|c|c|c|}
\hline Internal Faktor Strategi & Bobot & $\begin{array}{l}\text { Bobot } \\
\text { Relatif }\end{array}$ & Peringkat & $\begin{array}{c}\text { Skor } \\
\text { Pembobotan }\end{array}$ \\
\hline \multicolumn{5}{|l|}{ Kekuatan } \\
\hline $\begin{array}{l}\text { - Luas Areal Tanaman Kelapa Dalam Cukup } \\
\text { Besar }\end{array}$ & 4,00 & 0,08 & 4,00 & 0,31 \\
\hline $\begin{array}{l}\text { - Petani Kelapa Dalam Memiliki Pengalaman } \\
\text { Kelapa Turun Temurun }\end{array}$ & 4,00 & 0,08 & 2,00 & 0,16 \\
\hline $\begin{array}{l}\text { - Tersedianya Jumlah Angkatan Kerja yang } \\
\text { Cukup Besar }\end{array}$ & 4,00 & 0,08 & 3,00 & 0,24 \\
\hline $\begin{array}{l}\text { - Telah Memiliki Industri Besar Pengolahan } \\
\text { Kelapa Dalam }\end{array}$ & 4,00 & 0,08 & 3,00 & 0,24 \\
\hline $\begin{array}{l}\text { - Tersedianya Balai Riset dan Standardisasi } \\
\text { Sebagai Lembaga Quality Control. }\end{array}$ & 2,00 & 0,04 & 3,00 & 0,12 \\
\hline \multicolumn{5}{|l|}{ Kelemahan } \\
\hline $\begin{array}{l}\text { - Umur Tanaman Kelapa Dalam Sudah } \\
\text { Banyak Yang Tua }\end{array}$ & 4,00 & 0,08 & 2,00 & 0,16 \\
\hline $\begin{array}{l}\text { - Petani Kelapa Pada Umumnya Menggunakan } \\
\text { Bibit Lokal }\end{array}$ & 4,00 & 0,08 & 2,00 & 0,16 \\
\hline $\begin{array}{l}\text { - Produktivitas Tanaman Kelapa Dalam } \\
\text { Menurun }\end{array}$ & 4,00 & 0,08 & 2,00 & 0,16 \\
\hline $\begin{array}{l}\text { - Manajemen Usahatani Belum Dilakukan } \\
\text { Dengan Baik }\end{array}$ & 3,00 & 0,06 & 1,00 & 0,06 \\
\hline $\begin{array}{l}\text { - Banyaknya Trio Tata Air Yang Telah } \\
\text { Mengalami Kerusakan }\end{array}$ & 3,00 & 0,06 & 1,00 & 0,06 \\
\hline $\begin{array}{l}\text { - Masih Kurangnya Kualitas Infrastruktur } \\
\text { Jalan di Kabupaten Indragiri Hilir }\end{array}$ & 2,00 & 0,04 & 2,00 & 0,08 \\
\hline $\begin{array}{l}\text { - Terbatasnya Jumlah dan Jenis Diversifikasi } \\
\text { Produk Turunan Kelapa }\end{array}$ & 3,00 & 0,06 & 2,00 & 0,12 \\
\hline - Struktur Pasar Bersifat Monopsomi & 4,00 & 0,08 & 1,00 & 0,08 \\
\hline • Belum Terbentuknya Sistem Resi Gudang & 3,00 & 0,06 & 1,00 & 0,06 \\
\hline $\begin{array}{l}\text { - Terbatasnya Jumlah Kelembagaan } \\
\text { Pembinaan Petani Kelapa Dalam }\end{array}$ & 3,00 & 0,06 & 1,00 & 0,06 \\
\hline Total Nilai Pembobotan & 51,00 & $\mathbf{1 , 0 0}$ & & 2,04 \\
\hline
\end{tabular}

adanya dukungan PEMDA dan instansi terkait, namun demikian masih memiliki ancaman berupa tingginya perhatian investasi di negara kompetitor Indonesia terhadap industri perkelapaan serta kerusakan lahan perkebunan kelapa akibat intrusi air laut.

Peluang tersebut di atas tidak dapat diraih bilamana hal yang mengancam tersebut tidak diminimalisir oleh pihak pemerintah. Untuk meningkatkan peluang tersebut perlu adanya perhatian yang cukup serius dari pihak pemerintah terhadap investasi produk kelapa dan turunannya yang masih bisa dikembangkan dan mempunyai permintaaan pasar yang cukup tinggi di pasaran ekspor dengan cara pembangunan pabrik industri pengolahan kelapa secara terpadu dengan program kemitraan anatar petani kelapa, pengusaha industri kecil dan industri besar pengolahan kelapa di Kabupaten Indragiri Hilir.

Strategi lainnya yang perlu dilaksanakan oleh pihak pemerintah untuk meraih peluang tersebut diatas adalah dengan melaksanakan perbaikan trio tata air yang merusak kebun kelapa rakyat, peremajaan kebun kelapa masyarakat yang rusak dengan cara memberikan bantuan bibit kelapa dalam unggul lokal kepada masyarakat yang terkena dampak intrusi air laut sehingga produk dan produktivitas tanaman kelapa yang dihasilkan meningkat dan kebutuhan bahan baku untuk industri kecil dan industri besar pengolahan 
Tabel 2. Total Score External Factor Analysis (EFAS)

\begin{tabular}{|c|c|c|c|c|}
\hline External Faktor Strategi & Bobot & $\begin{array}{l}\text { Bobot } \\
\text { Relatif }\end{array}$ & $\begin{array}{c}\text { Pering } \\
\text { kat }\end{array}$ & $\begin{array}{c}\text { Skor } \\
\text { Pembobotan }\end{array}$ \\
\hline \multicolumn{5}{|l|}{ Peluang } \\
\hline - Tingginya Permintaan Produk Kelapa dan & 4,00 & 0,19 & 3,00 & 0,57 \\
\hline $\begin{array}{l}\text { Turunannya di Pasaran Ekspor } \\
\text { - Produk Turunan Kelapa Masih Bisa }\end{array}$ & 4,00 & 0,19 & 3,00 & 0,57 \\
\hline $\begin{array}{l}\text { Dikembangkan } \\
\text { - Adanya Dukungan PEMDA dan Instansi Terkait }\end{array}$ & 4,00 & 0,19 & 3,00 & 0,57 \\
\hline $\begin{array}{l}\text { Terhadap Pengembangan Industri Tanaman } \\
\text { Kelapa }\end{array}$ & & & & \\
\hline \multicolumn{5}{|l|}{ Ancaman } \\
\hline $\begin{array}{l}\text { - Kerusakan Lahan Perkebunan Kelapa Akibat } \\
\text { Intrusi Air Laut }\end{array}$ & 3,00 & 0,14 & 1.00 & 0,14 \\
\hline - Produk Minyak Kelapa Tidak Dapat Bersaing & 2,00 & 0,10 & 1,00 & 0,10 \\
\hline $\begin{array}{l}\text { Dengan Produk Minyak Sawit. } \\
\text { - Tingginya Perhatian Investasi di Negara }\end{array}$ & 2,00 & 0.10 & 2,00 & 0,19 \\
\hline Kompetitor Indonesia Terhadap Industri & & & & \\
\hline $\begin{array}{ll} & \text { Perkelapaan } \\
\text { - Negara Pesaing Philippina }\end{array}$ & 2,00 & 0,10 & 1,00 & 0,10 \\
\hline Total Skor Pembobotan & 21,00 & $\mathbf{1 , 0 0}$ & & 2,24 \\
\hline
\end{tabular}

kelapa dapat terpenuhi dan jumlah serta jenis diversifikasi produk turunan kelapa dapat meningkat di pasaran ekspor.

\section{Matrik IE (Internal dan External) Hasil dari matrik IE dari nilai total}

Skor pembobotan pada analisa faktor internal dan external yang ditunjukkan pada
Gambar1, termasuk ke dalam sel ke V (lima) yaitu pengembangan industri kelapa di Kabupaten Indragiri Hilir dapat ditumbuhkan dengan cara melakukan integrasi secara horizontal dengan pengelolaan menggunakan strategi menjaga serta mempertahankan penetrasi pasar dan pengembangan produk yang ada.

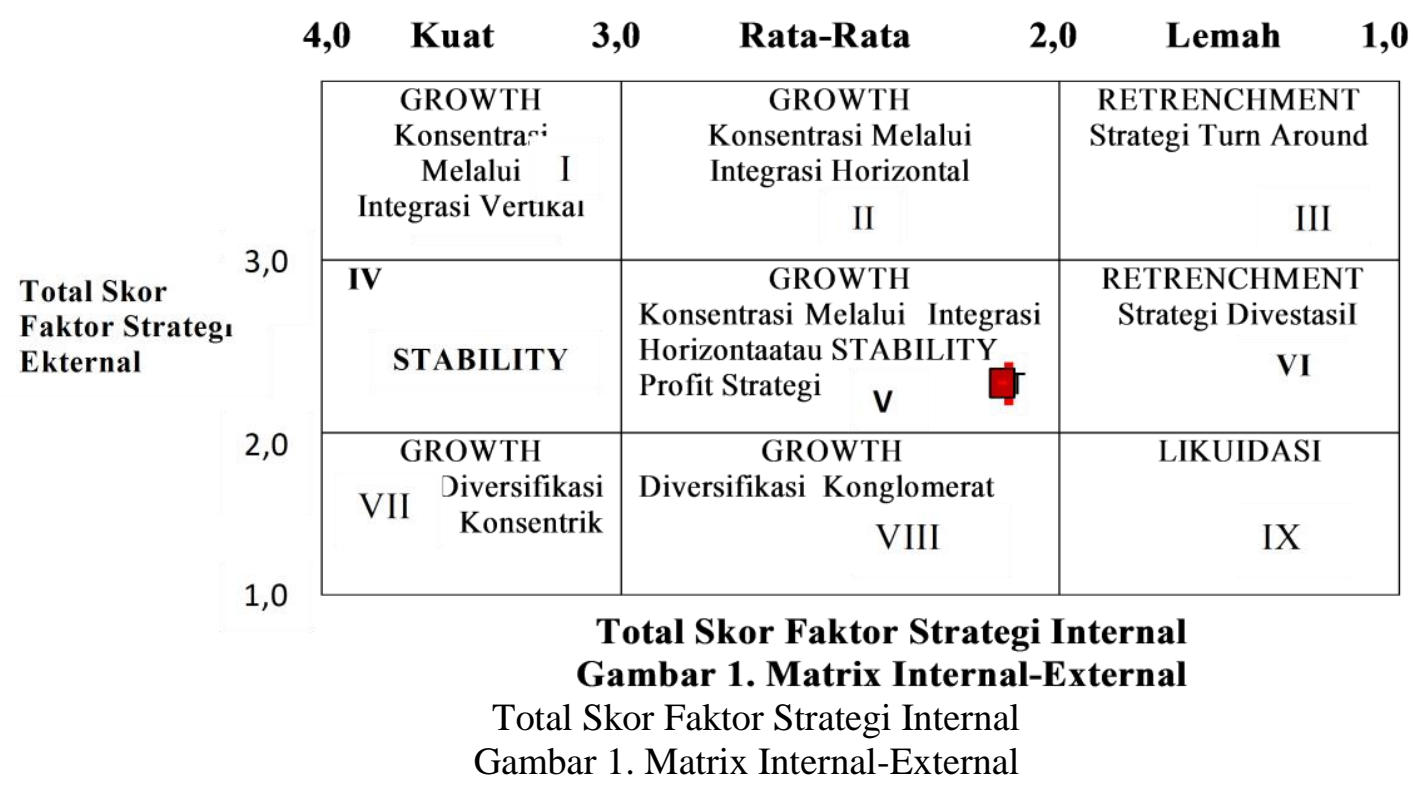


Strategi yang dapat dilakukan pada sel ini agar pengembangan industri kelapa yang ada di Kabupaten Indragiri Hilir dapat tumbuh dan dipertahankan adalah pihak Pemerintah Daerah perlu melaksanakan pembuatan Peraturan Daerah tentang perkelapaan antara lain: strategi pengaturan kembali tata niaga kelapa, membangun Sistem Resi Gudang serta menetapkan kembali harga jual kelapa bulat berdasarkan komponen-kpmponen yang terkandung dalam buah kelapa bulat sehingga keberadaan industri kelapa yang ada di Kabupaten Indragiri Hilir dapat dipertahankan dan dikembangkan.

\section{KESIMPULAN DAN SARAN}

\section{Kesimpulan}

Berdasarkan hasil penelitian yang telah dilakukan, maka dapat disimpulkan bahwa:

1) Faktor Internal yang menjadi kekuatan pengembangan industri kelapa adalah luas areal tanaman kelapa cukup besar, tersedianya tenaga kerja yang cukup besar dan adalah umur tanaman kelapa sudah banyak yang tua, . petani kelapa umumnya menggunakan bibit lokal, produktivitas tanaman kelapa menurun dan terbatasnya jumlah dan jenis diversifikasi produk turunan kelapa.

2) Faktor External yang menjadi peluang pada pengembangan industri kelapa adalah tingginya permintaan produk kelapa dan turunannya di pasar ekspor, produk turunan kelapa masih dapat dikembangkan dan adanya dukungan dari Pemerintah Daerah serta instansi terkait terhadap pengembangan industri kelapa, sedangkan faktor external yang menjadi anaman terhadap pengembangan industri kelapa di Kabupaten Indragiri Hilir adalah kerusakan lahan perkebunan akibat adanya intrusi air laut dan tingginya perhatian investasi di negara competitor terhadap industri perkelapaan.

\section{Saran}

Untuk Pengembangan industri kelapa di

Kabupaten Indragiri Hilir perlu disarankan kepada pihak pemerintah untuk melaksanakan implikasi kebijakan sebagai berikut:

1) Pihak pemerintah hendaknya melaksanakan strategi peremajaan tanaman kelapa dalam yang ada dengan menggunakan bibit unggul lokal sehingga produk dan produktivitas tanaman kelapa yang dihasilkan oleh masyarakat akan meningkat.

2) Pihak pemerintah perlu membuat strategi pengembangan industri kelapa secara terpadu dengan pola kemitraan antara petani kelapa, industri besar pengolahan kelapa dengan industri kecil pengolahan kelapa yang ada sehingga dapat meningkatkan jumlah dan jenis diversifikasi produk turunan kelapa yang mempunyai peluang ekspor di pasaran ekspor.

3) Implikasi kebijakan lainnya yang perlu dilakukan adalah pembuatan Peraturan Daerah tentang perkelapaan, melaksanakan pengaturan tata niaga kelapa bulat, pembangunan Sistem Resi Gudang, penetapan kembali harga jual kelapa berdasarkan komponen-komponen yang terkandung dalam buah kelapa bulat, melaksanakan strategi perbaikan trio tata air dan peremajaan tanaman kelapa masyarakatyang telah rusak, pemberian bantuan bibit unggul lokal sehingga produk dan produktivitas tanaman kelapa yang dihasilkan akan meningkat dan dapat memenuhi kebutuhan bahan baku untuk industri pengolahan kelapa yang ada di Kabupaten Indragiri Hilir.

\section{DAFTAR PUSTAKA}

Badan Pusat Statistik, 2015, Statistik Indonesia 2015, Jakarta

Badan Pusat Statistik Kabupaten Indragiri Hilir., 2015, Indragiri Hilir Dalam Angka Tahun 2015, Tembilahan.

Bakce, Djaimi et al., 2015, Model Pengembangan Agribisnis Kelapa Terpadu di Kabupaten Indragiri Hilir, Seminar Nasional Agribisnis, Bogor.

Damanik, Sabarman., 2007, Strategi Pengembangan Agribisnis Kelapa (Cocosnucifera) Untuk Meningkatkan Pendapatan Petani di Kabupaten Indragiri Hilir, Riau. Jurnal Perspektif 6(2): 99-104

Rangkuti, Freddy., 2001, Analisis SWOT: Teknik Membedah kasus Bisnis,Penerbit PT Gramedia Pustaka Utama, Jakarta.

Rencana Strategis Kementerian Pertanian Republik Indonesia Tahun 2015-2019, Kementerian Pertanian Republik Indonesia, 2015, Jakarta. 
